\title{
The Discovery of a Ureteral Bifidity during a Laparotomy
}

DERGAMOUN Hamza*, Ouskri Salim, Bellouki Omar, Hachem Al Sayegh, BENSLIMANE Lounis, NOUINI Yassine

Departement of Urology A, Mohammed 5 university, Faculty of Medicine and Pharmacy of Rabat Ibn Sina Teaching Hospital, Avenue Bettouga, Rabat, Morocco

DOI: $10.36347 /$ sasjs.2020.v06i04.007

| Received: 31.03 .2020 | Accepted: 08.04.2020 | Published: 11.04.2020

*Corresponding author: DERGAMOUN Hamza

\section{Abstract}

This paper treats the fortuitous discovery of a ureteral bifidity during a laparotomy.

Keywords: Ureteral bifidity laparotomy.

Copyright @ 2020: This is an open-access article distributed under the terms of the Creative Commons Attribution license which permits unrestricted use, distribution, and reproduction in any medium for non-commercial use (NonCommercial, or CC-BY-NC) provided the original author and source are credited.

\section{INTRODUCTION}

Ureteral bifidity is the presence of two ureters, from two half-kidneys, which join in one before entering the bladder. It is neither a pathology nor an anomaly, but a simple anatomical variant occurring in less than $1 \%$ of cases.

It does not generally cause any pathological consequence because the ureteral orifice is unique.

\section{Observation}

We report the case of a 67 year old patient admitted to the operating room to benefit from a total cystoprostatectomy after a bladder tumor infiltrating the muscle.

During the dissection with the aim of individualizing the ureter for the preparation of a bricker we discovered a bifidity at the expense of the left ureter which had passed unnoticed in the additional CT examinations.

The rest of the intervention was not changed and the two ureteries were brought to the skin via an ileal loop by mean of a wallace.

The patient was reviewed 1 month later, his condition and his biological balance were without anomalies.

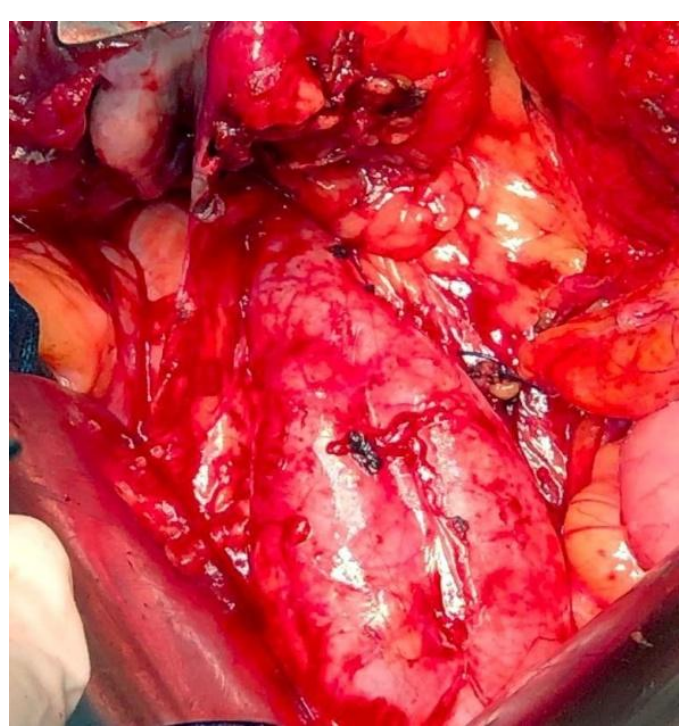

\section{DISCUSSION}

A bifid ureter is a congenital renal tract abnormality due to some error or disturbance during development [1].

Sometimes instead of having one urine drainage system between the kidney and the bladder there are two. There may even be, exceptionally, three; we then speak of triplication.

This double system can be complete or the two ureters an meet, more or less high, before their arrival in the bladder (there is only one opening in the bladder); we speak of pyelo ureteral bifidity or partial duplication. 


\section{Conclusion}

Having a dual system is not necessarily pathological and many will not be a problem. This is particularly the case with bifidity. Nevertheless, some complications have been reported such as: frequent urinary tract infection, uretero ureteric reflux, ureteric stenosis, urinary lithiasis, and pyelonephritis, nonfunctioning of kidney units [2].

\section{REFERENCES}

1 Souhail R, Amine S. Unilateral bifid ureter. The Pan African Medical Journal. 2016;25.

2 Costa A, Matter M, Pascual M, Doerfler A, Venetz JP. Renal, vascular and urological variations and abnormalities in living kidney donor candidates. Progres en urologie: journal de l'Association francaise d'urologie et de la Societe francaise d'urologie. 2019 Mar;29(3):166-72. 